\title{
Ectopic Expression of the Rhizobium etli amtB Gene Affects the Symbiosome Differentiation Process and Nodule Development
}

\author{
Rosarita Taté, ${ }^{1}$ Michele Cermola, ${ }^{1}$ Anna Riccio, ${ }^{1}$ Maurizio laccarino, ${ }^{1}$ Mike Merrick, ${ }^{2}$ Reneé Favre, ${ }^{1}$ \\ and Eduardo J. Patriarca ${ }^{1}$ \\ ${ }^{1}$ International Institute of Genetics and Biophysics, CNR, Via Marconi 10, 80125 Naples, Italy; ${ }^{2}$ Nitrogen \\ Fixation Laboratory, John Innes Centre, Norwich NR4 7UH, U.K. \\ Accepted 8 March 1999.
}

\begin{abstract}
Under conditions of nitrogen limitation, soil bacteria of the genus Rhizobium are able to induce the development of symbiotic nodules on the roots of leguminous plants. During nodule organogenesis, bacteria are released endocytotically inside the invaded plant cells where they differentiate into their endosymbiotic form called bacteroids. Bacteroids surrounded by a plant-derived peribacteroid membrane are nondividing, organelle-like structures, called symbiosomes, that use nitrogenase to reduce $\mathrm{N}_{2}$ to ammonia. Experiments performed in vitro with isolated symbiosomes have previously led to the suggestion that the $\mathrm{NH}_{3}$ produced by the bacteroids is released as $\mathrm{NH}_{4}{ }^{+}$into the plant cytosol. Furthermore, it was observed that the

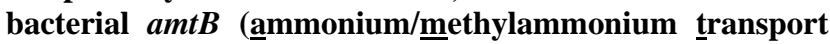
B) gene is switched off very early during symbiosis, just when bacteria are released into the host cells. We report here that the ectopic expression of $\mathrm{amtB}$ in bacteroids alters the ability of bacteria to invade the host cells and the symbiosome differentiation process. Both the NtrC protein, which controls the expression of the bacterial genes involved in $\mathrm{NH}_{4}{ }^{+}$assimilation, and the nitrogenase activity are essential to observe the $a m t B$-mediated effect. Our results support the idea that in vivo bacteroids do not take up $\mathrm{NH}_{4}^{+}$and demonstrate that the transcriptional downregulation of the amtB gene is essential for an effective symbiotic interaction.
\end{abstract}

Additional keyword: poly- $\beta$-hydroxybutyrate.

Bacteria of the genus Rhizobium are able to elicit the formation of nitrogen-fixing nodules on the roots of a legume plant. Nodule formation involves complex interactions between the bacterium and the host plant, from initial recognition and infection to nodule development and nodule function. Briefly, bacteria proliferate in the rhizosphere and infect the root by growing inside tubular structures called infection

Corresponding author: Eduardo J. Patriarca, International Institute of Genetics and Biophysics, CNR, Via Marconi 10, 80125 Naples, Italy; Telephone: +39-081-7257223; Fax: +39-081-7257319

E-mail: Patriarca@iigbna.iigb.na.cnr.it

Present address of Maurizio Iaccarino: UNESCO, 7 Place de Fontenoy, Paris, 75352, France. threads (ITs). Meanwhile, nearby cortical cells de-differentiate and, after various mitotic steps, form a nodule primordium that is reached by the ITs. Bacteria are released endocytotically from the ITs into the cytoplasm of the invaded host cells where, surrounded by a peribacteroid membrane (PBM) of plant origin (which controls the nutrient transfer between the symbionts), they differentiate into nitrogen-fixing symbiosomes (i.e., they are able to reduce atmospheric dinitrogen $\left[\mathrm{N}_{2}\right]$ to ammonia $\left.\left[\mathrm{NH}_{3}\right]\right)$ through the activation of the nitrogenase complex (for reviews, see Verma 1992; Panagiota et al. 1995; Van Rhijn and Vanderleyden 1995).

One of the most important aspects of this type of endosymbiotic association is the identification of the molecular mechanism by which bacteroids are able to fix nitrogen but, unlike free-living diazotrophs, are unable to assimilate the $\mathrm{NH}_{3}$ produced. In fact, although it was suggested some time ago that most of the fixed-nitrogen produced by the symbiosomes is exported to the host plant to satisfy its demands for nitrogen (Glenn and Dilworth 1984), the form (e.g., $\mathrm{NH}_{3} / \mathrm{NH}_{4}{ }^{+}$or organic compounds, such as amino acids) and the mechanism (passive diffusion or active transport) by which nitrogen is exported are still largely unclear. However, it has recently been proposed (see Figure 1; Udvardi and Day 1997) that $\mathrm{NH}_{3}$ might passively diffuse across the bacteroid membrane into the relatively acidic peribacteroid space (PBS) where it is converted to $\mathrm{NH}_{4}^{+}$, which then enters the plant cytosol through a channel located on the PBM. This model was based on previous observations indicating that the $\mathrm{NH}_{4}{ }^{+}$assimilation activities of isolated bacteroids, such as $\mathrm{NH}_{4}{ }^{+}$uptake (AMT) and glutamine synthetase (GS) activities, are expressed at very low levels in $\mathrm{N}_{2}$-fixing bacteroids (for a review, see Udvardi and Day 1997) and on the identification of an $\mathrm{NH}_{4}{ }^{+}$carrier (identified by the patch clamp technique) located on the PBM (Tyerman et al. 1995; Kaiser et al. 1998).

In Rhizobium etli it has previously been demonstrated that the transcription of genes involved in $\mathrm{NH}_{4}{ }^{+}$assimilation is regulated by the two-component Ntr system (for a review, see Merrick and Edwards 1995) including the histidine protein kinase NtrB and the transcriptional regulator NtrC (Patriarca et al. 1992, 1993, 1994). Furthermore, it has been observed (Patriarca et al. 1996; Taté et al. 1998) that this system is switched off in $R$. etli bacteria growing inside the Phaseolus vulgaris (common bean) nodule, by a three-step mechanism of 
gene regulation acting firstly by inactivation of the NtrC protein (most probably by de-phosphorylation), secondly by down-regulation of $n t r C$ transcription occurring in bacteroids of young symbiosomes, and thirdly by the complete removing of NtrC protein by an unknown mechanism of protein degradation. Therefore, it was suggested (Taté et al. 1998) that the inactivation of $\mathrm{NtrC}$ may be the first step of a regulatory mechanism of gene regulation acting during bacteroid differentiation to uncouple $\mathrm{N}_{2}$ fixation and $\mathrm{NH}_{4}{ }^{+}$assimilation activities (see Figure 1). Two other lines of evidence support this mechanism: firstly, an $n t r C$ mutant strain of $R$. etli forms very efficient nitrogen-fixing nodules (Moreno et al. 1992), thus indicating that, unlike free-living diazotrophs, nif genes may be activated independently of the general $n t r$ system. Secondly, the expression in $R$. etli of the Escherichia coli gdh (glutamate dehydrogenase) gene interferes with nodulation and with nitrogen fixation (Bravo et al. 1988; Mendoza et al. 1995, 1998).

Homologues of the $a m t B\left(\mathrm{NH}_{4}{ }^{+} / \mathrm{CH}_{3} \mathrm{NH}_{3}{ }^{+}\right.$transport $)$gene have been cloned and characterized from various organisms, including yeast (Marini et al. 1994), plants (Ninneman et al. 1994), and bacteria (Siewe et al. 1996; Van Heeswijk et al. 1996; Taté et al. 1998). In bacteria the $a m t B$ gene product (which is predicted to encode a membrane protein of around $54 \mathrm{kDa}$, with 10 to 12 transmembrane domains) is required for transport (uptake activity) of $\mathrm{NH}_{4}{ }^{+} / \mathrm{CH}_{3} \mathrm{NH}_{3}{ }^{+}$(Siewe et al. 1996) and for growth at low $\mathrm{NH}_{3}$ concentrations (Soupene et al. 1998). In $R$. etli the $a m t B$ gene is transcribed from an NtrCdependent promoter that, during the symbiotic interaction, is active in bacteria growing inside the ITs, but is switched off just when bacteria are released inside the invaded host cells (Taté et al. 1998). We correlated the down-regulation of $a m t B$ expression with the absence of an active transport mechanism for the uptake of $\mathrm{NH}_{4}{ }^{+}$ions previously observed with isolated symbiosomes (Brown and Dilworth 1975; Laane et al. 1980; Howitt et al. 1986) and predicted that forcing the expression of $a m t B$ in $\mathrm{N}_{2}$-fixing bacteroids should retrieve at least part of the $\mathrm{NH}_{4}^{+}$present in the $\mathrm{PBS}$, thus generating an energyconsuming, futile cycle with negative consequences for the symbiotic association (see Figure 1). In this work we have tested this hypothesis by expressing $a m t B$ ectopically in bacteroids under the control of the $\mathrm{R}$. etli nifHc promoter (nifH codes for a nitrogenase subunit; Quinto et al. 1985). The consequence of this ectopic expression of $a m t B$ was analyzed by measuring the nitrogenase activity of fresh nodules and the effect on bacteroid differentiation and nodule development observed at the structural and ultrastructural levels.

\section{RESULTS}

\section{Effect of amtB expression on the nodulation efficiency of $\boldsymbol{R}$. etli.}

To test the effect of the ectopic expression of the $R$. etli $a m t B$ gene in bacteroids, various derivatives of plasmid pTR102 were constructed (Fig. 2A). These plasmids were transformed into the wild-type strain, CE3, of $R$. etli and the resulting strains were tested for their nodulation behavior. At the earliest time checked, 12 dpi (days post inoculation), the plants inoculated with strain CE3-pRT142 (pnifH-amtB) had produced root nodules, but of a smaller size than nodules formed by the control strains (CE3-pTR102, CE3-pRT140, CE3-pAR187, CE3-pAR188) (Fig. 3A, B). Later on, at 21 dpi, the nodules elicited by CE3-pRT142 never reached the size of the control and became oval in shape (Fig. 4A, B). Moreover, the nodules showed an abnormal pigmentation, being generally pale inside (ranging in color from off-white to tan or slightly pink), compared with nodules formed by the control strains, thus indicating a deficiency in leghemoglobin content.

To test the expression of $a m t B$ gene during nodulation, bacteroids were isolated from nodules ( $21 \mathrm{dpi})$ elicited by strain CE3-pRT142 or by the strains used as a control (CE3pTR102, CE3-pRT140, CE3-pAR187), and tested for their ability to accumulate $\left[{ }^{14} \mathrm{C}\right]$ methylammonium (used as an $\mathrm{NH}_{4}{ }^{+}$ analogue). Transport activity was calculated from measurements of accumulated radioactive label in bacteroids incubated at $30^{\circ} \mathrm{C}$ in minimal medium ( $\mathrm{pH}$ 6.5) with $100 \mu \mathrm{M}$ $\left[{ }^{14} \mathrm{C}\right]$ methylammonium, as previously described (Taté et al. 1998). Under these conditions, bacteroids of strain CE3pRT142 showed significant $\left[{ }^{14} \mathrm{C}\right]$ methylammonium uptake activity $\left(0.6 \mathrm{nmol} \mathrm{min} \mathrm{mg}^{-1}\right)$, whereas the bacteroids of strains used as a control had no significant activity. Therefore, we concluded that the $a m t B$ gene is expressed in bacteroids carrying plasmid pRT142 (pnifH-amtB).

The nitrogenase activity of fresh nodules was tested (Fig. 2B) by measuring the acetylene reduction activity (ARA). At 12 dpi the nodules formed by CE3-pRT142 showed very low (almost undetectable) levels of ARA, whereas nodules induced by the control strains showed significant levels of
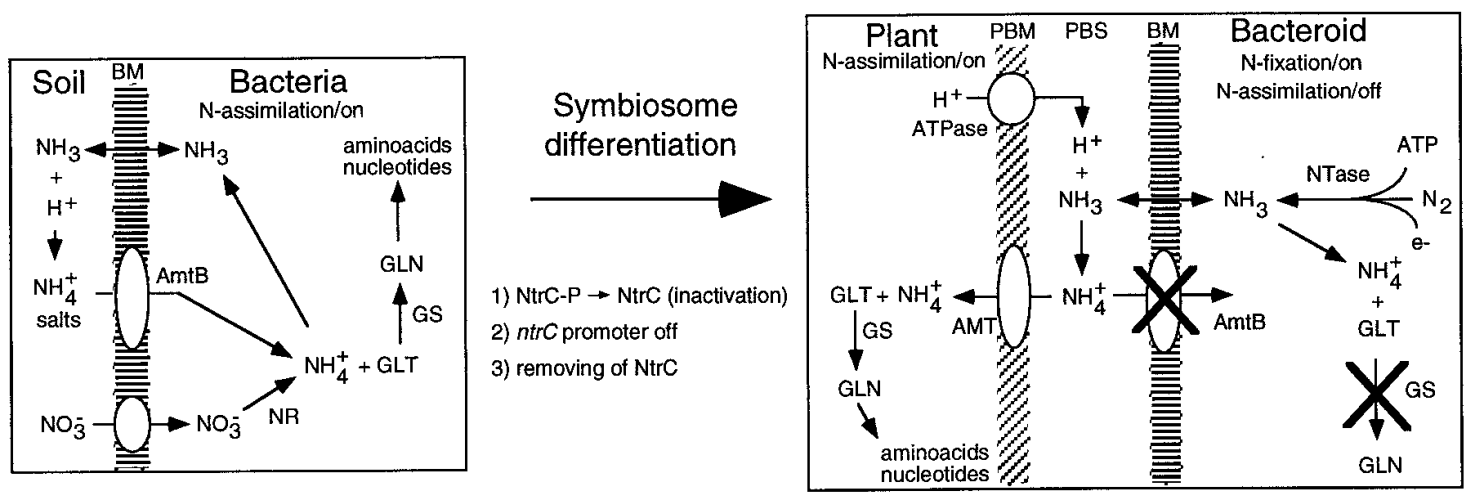

Fig. 1. The current model of $\mathrm{NH}_{4}{ }^{+}$transport from the $\mathrm{N}_{2}$-fixing symbiosome to the cytoplasm of the invaded plant cell; nitrogenase (Ntase), glutamine (GLN), glutamate (GLT), peribacteroid membrane (PBM), peribacteroid space (PBS), glutamine synthetase (GS). 
ARA. The ARA of 15-, 21-, and 28-dpi nodules is shown in Figure 2B. Even though the ARA of nodules formed by CE3pRT142 increased with time, it never reached more than $25 \%$ of the activity of the control nodules. Nodules elicited by one of the strains, CE3-pAR187 (carrying a partially deleted $a m t B$ gene), showed a delay in ARA induction (about $60 \%$ of the control ARA at $21 \mathrm{dpi}$ ) but the activity was at all times significantly higher than that of CE3-pRT142 induced nodules.

\section{Effect of amtB expression on nodule organogenesis.}

Cross-sections of resin-embedded nodules were examined by light and electron microscopy. At $12 \mathrm{dpi}$, the nodules induced by the strains used as control (CE3 carrying either pTR102, pRT140, pAR187, or pAR188) were already full of infected cells with a normal morphology for this stage of nodule organogenesis (Fig 3C; Taté et al. 1994). By contrast, nodules induced by CE3-pRT142, though having an apparently normal morphology to the naked eye, were smaller (Fig. $3 \mathrm{~A}, \mathrm{~B})$ and histological examination showed them to contain a large central zone with spherical masses of cytoplasm-rich cells having no visible infection (Fig. 3D). Most of these cells, which were smaller than the invaded cells formed by the control strains (Fig. 3C, E), contained a large nucleus, a prominent nucleolus, and densely staining cytoplasm containing only small vacuoles. The uninfected cells also showed large accumulations of starch grains (Fig. 3D). The few nodule cells invaded with CE3-pRT142 were present only as small patches surrounded by many layers of uninfected cells (Fig. 3F). The cytoplasm of these rare infected cells contained a very low number of undifferentiated symbiosomes (Fig. 5B).
At 21 dpi, the nodules formed by CE3-pRT142 contained a lower ratio of invaded to uninvaded cells than the control nodules (Fig. 4C, D). At this stage, nodules elicited by CE3pRT142 contained all the tissues found in a mature bean nodule (Taté et al. 1994), including peripheral vascular bundles, a layer of schlerenchymatic cells, and a central tissue (Fig. 4D). In the central tissue the uninfected cells had a normal size and showed large accumulations of starch, while the infected cells were apparently still in the process of being invaded (Fig. 4D). In these invaded cells the cytoplasm contained fewer symbiosomes (Fig. 4E, F) with 1 or 2 bacteroids per symbiosome, compared with 2 to 4 in the control nodules. Most bacteroids were like rod-shaped dividing bacteria, with a higher density of ribosomes and a lower accumulation of poly$\beta$-hydroxybutyrate (PHB) vesicles. However, a heterogeneous population of symbiosomes expressing various stages of early development was also observed, with the bacteroids never reaching the maturity seen in the controls (Fig. 5C, D). The maximum stage of morphological differentiation shown by a symbiosome of strain CE3-pRT142 at 21 dpi (Fig. 5D) can be compared with the homogenous stage of symbiosomes observed in the controls at 12 dpi (Fig. 5A).

\section{The $n \operatorname{tr} C$ gene and the nitrogenase activity are required for the $a m t B$-mediated effect.}

In order to examine whether the phenotype caused by ectopic amt $B$ expression requires bacterial $\mathrm{NH}_{4}{ }^{+}$assimilation we tested the effect of pRT142 on the nodulation efficiency of strain CFN2012 (ntrC::Tn5), which has a pleiotrophic phenotype including lower intracellular levels of GS activity (Moreno et al.
A
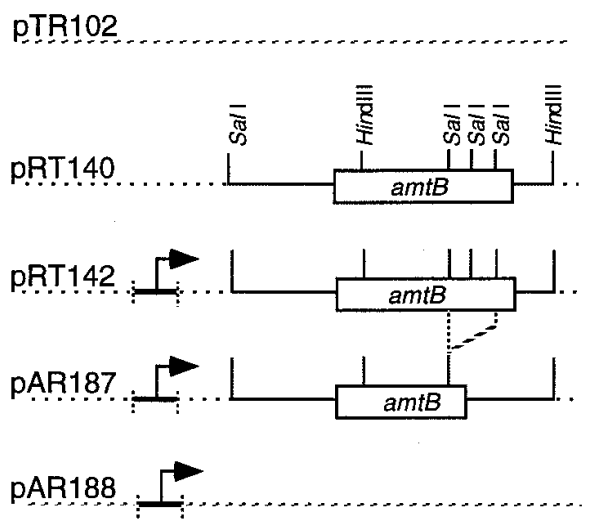

nifHc promoter
B

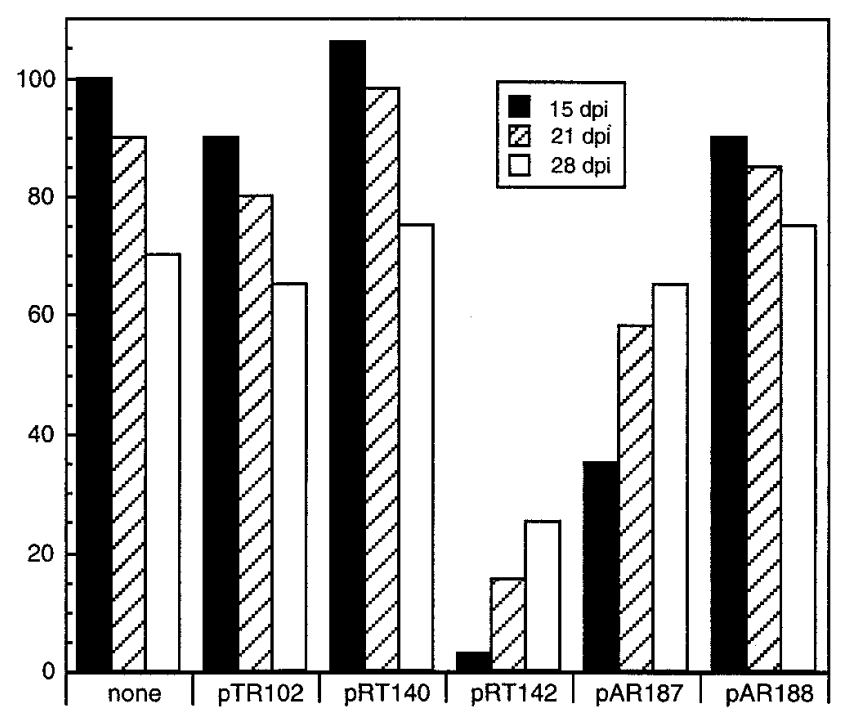

Fig. 2. A, Schematic rapresentation of the plasmid used to transform Rhizobium etli. All plasmids are derivatives of plasmid pTR102 and in all cases the DNA fragments were cloned into the BamHI site (see Material and Methods). These plasmids were used to transform the wild-type strain of $R$. etli; with the resulting strains nodulation tests on the roots of common beans (Phaseolus vulgaris) were performed. B, At 15, 21, or 28 days post inoculation (dpi), the nitrogenase activity measured as acetylene reduction activity (ARA) of nodules elicited by strain CE3, CE3/pTR102 (carrying the vector alone), CE3/pRT140 (the $a m t B$ gene without promoter), CE3/pRT142 (amtB under the control nifHc promoter), CE3/pAR187 (a deleted version of $a m t B$ under the control of pnifHc), CE3/pAR188 (the pnifHc alone). Values are expressed as percentage of the ARA measured with 15-dpi nodulated roots elicited by strain CE3 alone (none). To determine the ARA of a strain, three independent experiments with 10 nodulated roots each time were performed. In any case, values differ up to $\pm 20 \%$ of the value indicated. In some experiments, the ARA of 15 -dpi nodules induced by strain CE3/pRT142 was almost undetectable. 
1992; Patriarca et al. 1992, 1993; Taté et al. 1998). At 12 dpi the nodules elicited by CFN2012-pRT142 showed almost the same symbiotic phenotype (i.e., nodule number, shape, color, and ARA) as that observed in the nodules elicited by strain CE3-
pAR187. It was also observed that, unlike that observed in 12 dpi nodules elicited by strain CE3-pRT142, the invaded cells of 12-dpi nodules formed by CFN2012-pRT142 were already full of symbiosomes (Fig. 6B).
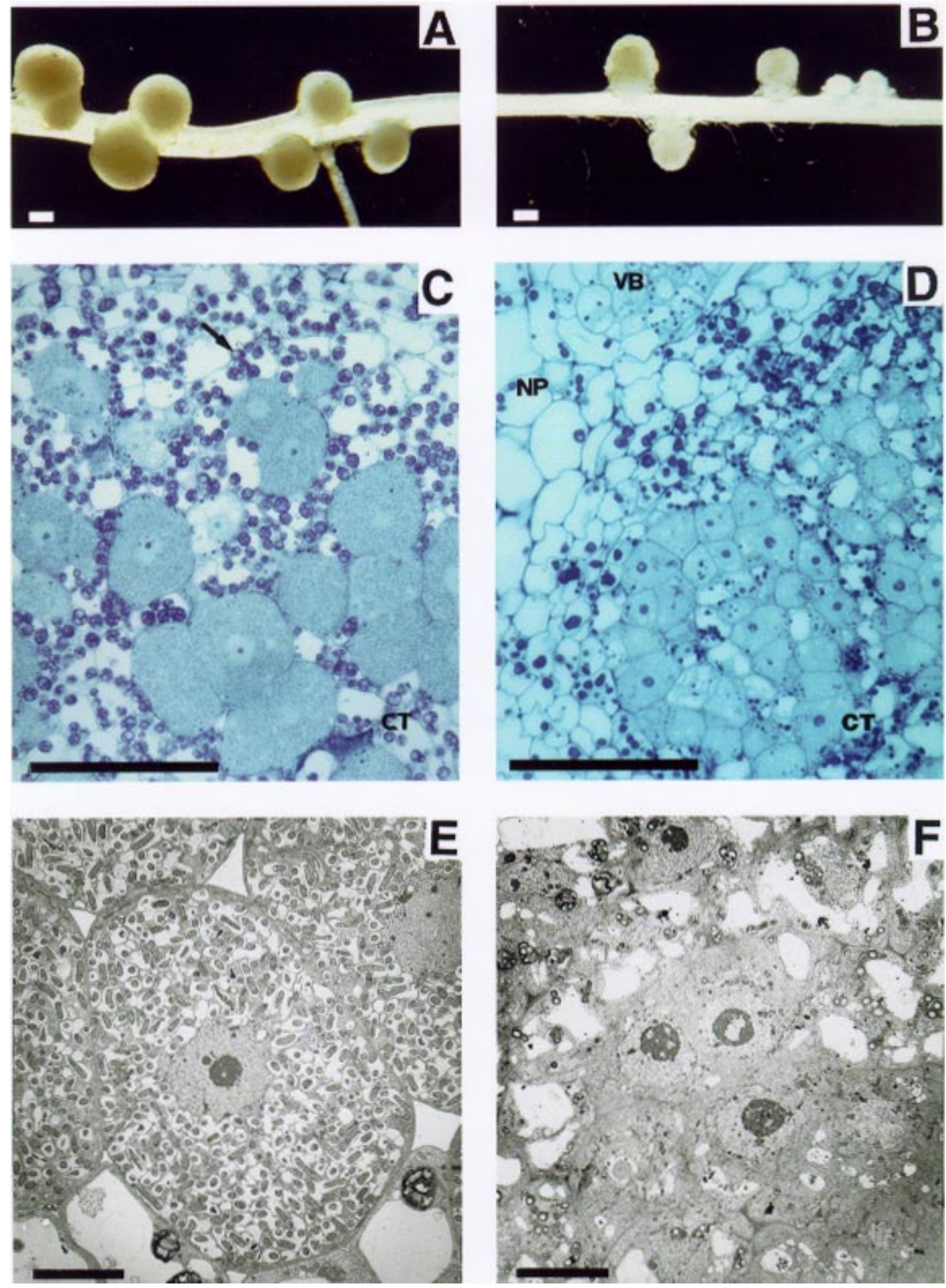

Fig. 3. A-F, Nodules (12 days post inoculation) elicited by the Rhizobium etli strains (A, C, and E) CE3-pRT140 or (B, D, and F) CE3-pRT142 on the root of Phaseolus vulgaris. A and $\mathbf{B}$, Whole roots were fixed with paraformaldehyde, cleared with sodium hypochlorite, and viewed by bright-field microscopy. C and D, Sections (1 to $2 \mu \mathrm{m}$ ) of Poly/Bed 812-embedded nodules were stained with toluidine blue and observed by light microscopy. $\mathbf{E}$ and F, Ultrathin sections were stained with uranyl acetate and lead citrate and observed by electron microscope. The starch grains (arrow), nodule vascular bundles (VB), nodule parenchyma (NP), and central tissue (CT) are indicated. Scale bars $=(\mathbf{A}-\mathbf{D}) 200$ or $(\mathbf{E}$ and $\mathbf{F}) 20 \mu \mathrm{m}$. 

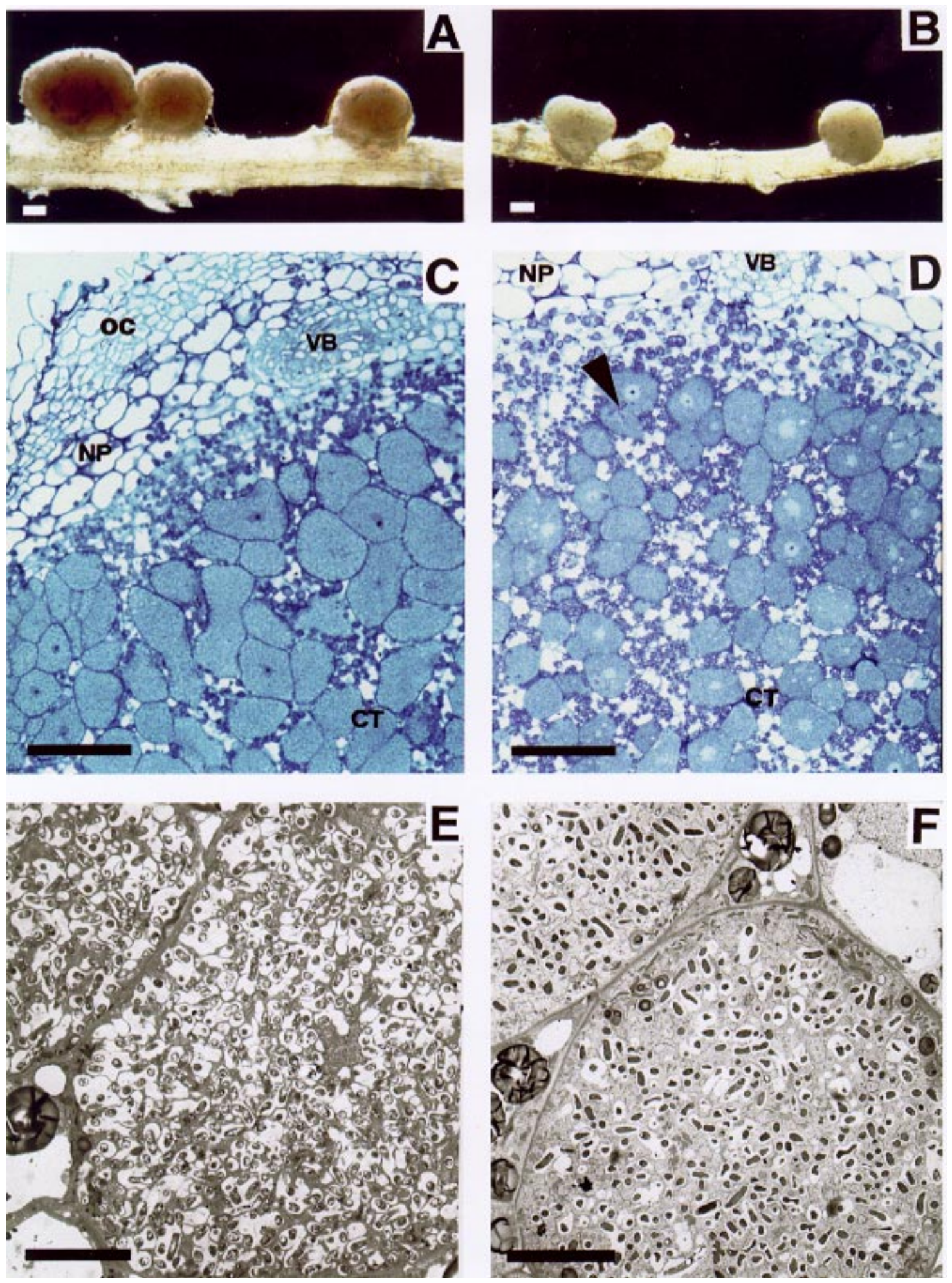

Fig. 4. A-F, Nodules (21 days post inoculation) elicited by the Rhizobium etli strains (A, C, and E) CE3-pRT140 or (B, D, and F) CE3-pRT142 on the root of Phaseolus vulgaris. A and $\mathbf{B}$, Whole roots were fixed with paraformaldehyde, cleared with sodium hypochlorite and viewed by brightfield microscopy. C and $\mathbf{D}$, Sections (1 to $2 \mu \mathrm{m}$ ) of Poly/Bed 812-embedded nodules were stained with toluidine-blue and observed by light microscopy. $\mathbf{E}$ and $\mathbf{F}$, Ultrathin sections were stained with uranyl acetate and lead citrate and observed by electron microscope. The infection threads (arrow head), nodule vascular bundles (VB), nodule parenchima (NP), nodule outer cortex (OC), and central tissue (CT) are indicated. Scale bars = (A-D) 200 or $(\mathbf{E}$ and $\mathbf{F}) 20 \mu \mathrm{m}$. 
To test whether the phenotype caused by ectopic amtB expression requires the nitrogenase activity, the effect of pRT142 on the nodulation efficiency of a Fix mutant of $R$. etli, strain CFNX249, was tested. At $12 \mathrm{dpi}$, the nodules elicited by CFNX249-pRT142 showed almost the same symbiotic phenotype (i.e., nodule shape and color) as that observed in the nodules elicited by the strains used as control (CE3 carrying either pTR102 or pRT140). However, the nodules (12 dpi) formed by CFNX249-pRT142 showed undetectable levels of ARA, whereas the invaded cells were already full of symbiosomes (Fig. 6C).

\section{The activity of $R$. etli pnifHc at different stages of nodule development.}

To determine the specificity and the timing of nifHc promoter (pnifHc) activity during nodule development, the wildtype strain of $R$. etli was transformed with plasmid pRT123 carrying a nifHc-lacZ fusion (Taté et al. 1998) and pAR66 carrying a transcriptional fusion between the promoter of the $n t r B C$ operon and lacZ (Patriarca et al. 1993). Under freeliving aerobic conditions of growth, strain CE3-pRT123 showed no significant $\beta$-galactosidase activity in any of the growth conditions tested (such as nitrogen or carbon starvation, etc.), whereas the strain used as a control (CE3-pAR66) had significant activity under all conditions tested (Patriarca et al. 1993, 1996). During the symbiotic interaction pnifHc is active in symbiosomes inside invaded cells in the central part of the central tissue and this activity is already evident at 8 to $9 \mathrm{dpi}$, when the nodule primordium is just emerging from the root and is visible to the naked eye (Fig. 7C); no activity is detected in undifferentiated bacteria growing inside the ITs (Fig. 7A, B). By contrast, the $n t r B C$ promoter is active in bacteria in the ITs and in symbiosomes inside the invaded host cells (Fig. 7D-F).

\section{DISCUSSION}

Implications for fixed nitrogen flux in the symbiosome.

A model of $\mathrm{NH}_{4}^{+}$flux during symbiosis has previously been proposed (Udvardi and Day 1997) based essentially on experiments performed with isolated symbiosomes (Fig. 1). In this model the $\mathrm{NH}_{3}$ produced in the bacteroids by the nitrogenase complex would diffuse to the PBS, where it would be converted to $\mathrm{NH}_{4}{ }^{+}$. These $\mathrm{NH}_{4}{ }^{+}$ions would pass from the PBS through an $\mathrm{NH}_{4}{ }^{+}$channel located in the PBM and would be rapidly fixed into amino acids in the cytoplasm of the plant cell. The function and capacity of the symbiosome to export $\mathrm{NH}_{4}{ }^{+}$depend on the following conditions: (i) a low level of ammonium assimilation activities, such as GS activity, in bacteroids; (ii) the presence of $\mathrm{NH}_{3}$ and $\mathrm{NH}_{4}^{+}$in the PBS; (iii) the absence of an $\mathrm{NH}_{4}{ }^{+}$uptake system in the bacteroid membrane; (iv) the presence of an $\mathrm{NH}_{4}{ }^{+}$carrier in the PBM; and (v) a high level of $\mathrm{NH}_{4}{ }^{+}$assimilation activities (e.g., GS) in the cytoplasm of the invaded plant cell. We hypothesized that inducing the ectopic expression of the amtB $\left(\mathrm{NH}_{4}{ }^{+} \mathrm{CH}_{3} \mathrm{NH}_{3}{ }^{+}\right.$transport) gene in bacteroids might help to confirm this model. The bacteroid $\mathrm{NH}_{4}{ }^{+}$carrier should compete with the channel located on the PBM of the symbiosome for $\mathrm{NH}_{4}{ }^{+}$ions present in the PBS (see Figure 1), though obviously the proportion of $\mathrm{NH}_{4}{ }^{+}$retrieved by the
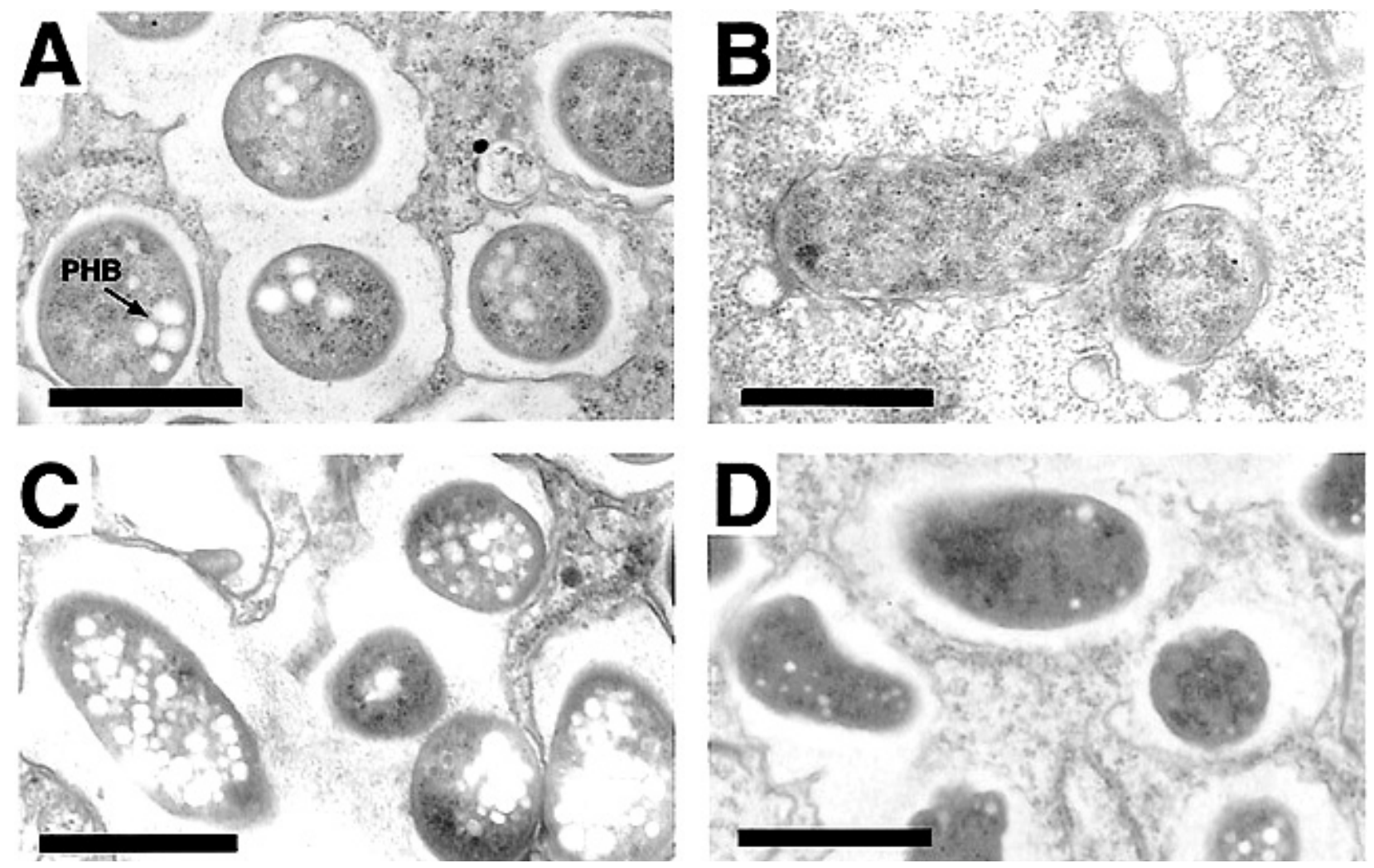

Fig. 5. A-D, Ultrastructural differentiation of bacteroids of nodules elicited by strain (A and C) CE3-pRT140 or (B and D) CE3-pRT142 at (A and B) 12 or (C and D) 21 days post inoculation. Deposits of poly- $\beta$-hydroxybutyrate $(\mathrm{PHB})$ are indicated. Scale bars $=2 \mu \mathrm{m}$. 
bacteroids should be dependent on the relative capacities of both carriers (their affinities, abundance, etc.).

In 15-dpi nodules elicited by the wild-type strain CE3 of $R$. etli expressing $a m t B$ ectopically, the nitrogenase activity (ARA) was less than $5 \%$ of the control and this only increased to $20 \%$ of the control in 21-dpi nodules (Fig. 2B). Moreover, comparing the ARA of nodules elicited by strain CE3-pRT140 (amtB alone) and CE3-pRT142 (pnifHc-amtB), it is clear that the nodule function was altered only when the expression of $a m t B$ was driven by pnifHc. In $R$. etli, the transcriptional activator NifA is absolutely required for both the induction of the pnifHc and an effective symbiosis (Valderrama et al. 1996). Thus, the low ARA observed with CE3-pRT142 (pnifHc-amtB) could be due to titration of NifA in bacteroids by the presence of extra copies of the NifA-dependent promoter. However, nodules formed by strain CE3-pAR188 (pnifHc alone) showed a normal morphology and ARA, allowing us to exclude that the phenotype observed is due to the titration of NifA.

It was observed that only strain CE3-pAR187 showed a delay in the kinetics of ARA induction, compared with the control nodules. Plasmid pAR187, carrying a deleted version of $a m t B$ under the control of pnifHc, should express a truncated AmtB protein lacking 2 of the 12 putative transmembrane domains. We observed that, unlike the intact gene, this deleted version of $a m t B$ is unable to rescue the lacks of transport of $\left[{ }^{14} \mathrm{C}\right]$ methylammonium (an $\mathrm{NH}_{4}{ }^{+}$analogue) shown by bacteroids. Moreover, nodules formed by strain CFN2012pRT142 (strain CF2012 is impaired in $\mathrm{NH}_{4}{ }^{+}$assimilation) or CFNX249-pRT142 (strain CFNX249 is a Fix ${ }^{-}$mutant) showed a symbiotic phenotype comparable to (or less marked than) that observed in nodules elicited by strain CE3-pAR187 (Fig. 6). Therefore, although the phenotype caused by ectopic expression of $a m t B$ is, at least in part, due to a nonspecific mechanism (i.e., independent of its function in the $\mathrm{NH}_{4}{ }^{+} / \mathrm{CH}_{3} \mathrm{NH}_{3}{ }^{+}$transport mechanism), it appears that the complete effect depends not only on the presence of an intact version of the $a m t B$ gene, but also on the capacity of bacteria to fix nitrogen (i.e., to produce $\mathrm{NH}_{4}{ }^{+}$) and to assimilate $\mathrm{NH}_{4}{ }^{+}$.
The timing of nif gene expression in determinate nodules.

One of the earliest and most remarkable consequences of the ectopic expression of $a m t B$ during symbiosis (simultaneous induction of $a m t B$ and nif genes) is the presence, in 12-dpi nodules, of a reduced number of invaded cells containing only a few symbiosomes (Fig. 3F). Moreover, the few symbiosomes observed showed all the morphological characteristics of free-living bacteria (Fig. 5B). This low number of undifferentiated symbiosomes indicates that the induction of pnifHc occurs at a very early stage of nodule invasion, that is, in bacteria growing inside the ITs or just released inside the plant cells. When a pnifHc-lacZ fusion was tested, it was observed (Fig. 7) that pnifHc is inactive in bacteria located inside the ITs but is active in bacteroids of about 8- to 9-dpi nodules, which are emergent, spherical structures containing few invaded cells. This result was quite unexpected but allowed us to identify a previously unrecognized difference between determinate and indeterminate nodules that differ considerably in their developmental patterns.

It has been well established that, in indeterminate nodules, symbiosomes occupy most of the cell volume of the invaded plant cells before activation of transcription of the nif genes (Vasse et al. 1990; Yang et al. 1991). This is also true when the activity of $\mathrm{R}$. etli pnifHc is tested during development of indeterminate nodules, induced by Rhizobium leguminosarum bv. viciae on the roots of Vicia hirsuta (Patriarca et al. 1996). By contrast, the results presented here clearly shown that, in determinate nodules, such as those induced by $R$. etli on common beans, the activation of at least nifHc takes place during the invasion process (i.e., before the invaded cells are filled with symbiosomes).

It was previously observed that the $\mathrm{R}$. etli pnifHc is induced in an NifA-dependent manner under low oxygen (1\%) concentration (Valderrama et al. 1996). Since the induction of pnifHc also depends on nifA during symbiosis it is reasonable to speculate that during symbiosis this promoter is activated in response to a drop in the oxygen tension. The microaerobic environment should therefore be generated inside the emer-
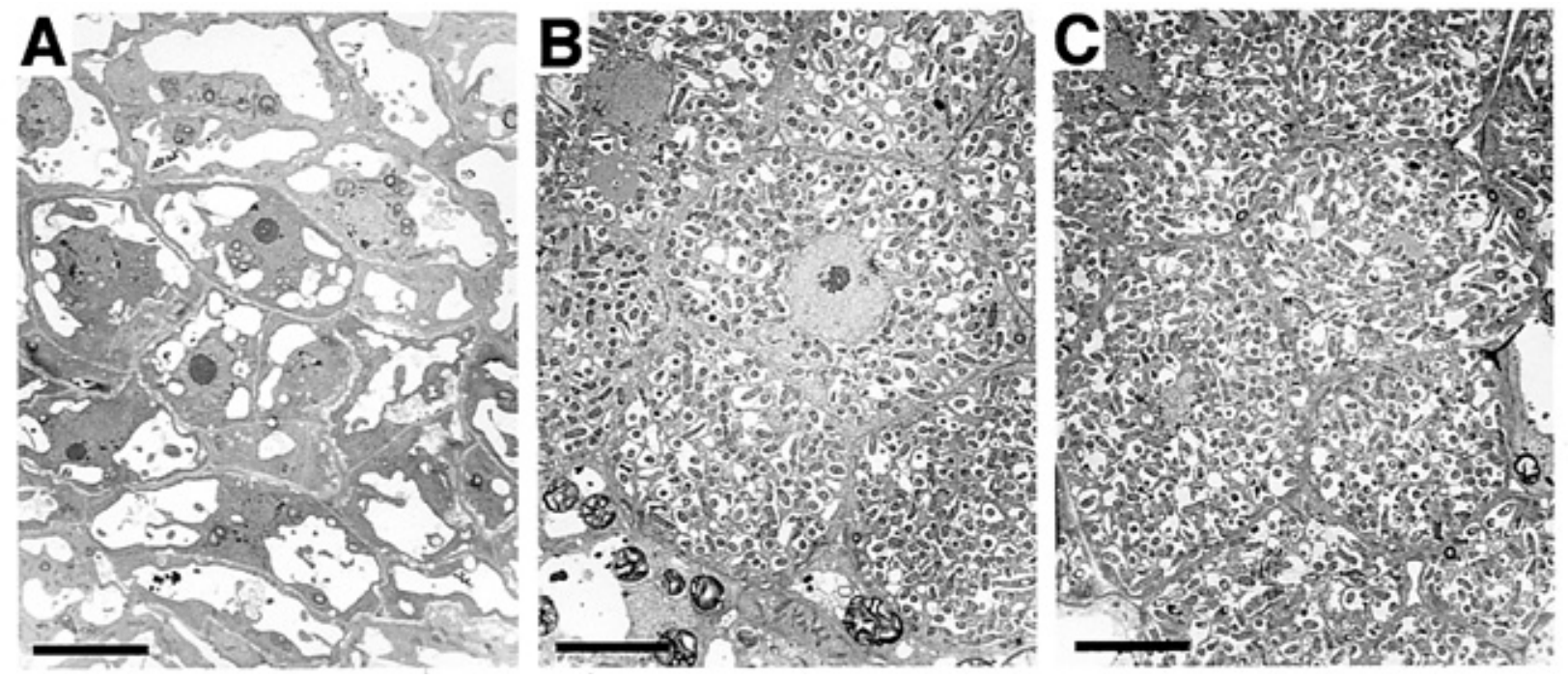

Fig. 6. A-C, Sections of nodules (12 days post inoculation) elicited by the Rhizobium etli strains (A) CE3-pRT142, (B) CFN2012-pRT142, or (C) CFNX249-pRT142 on the root of Phaseolus vulgaris. Ultrathin sections of Poly/Bed 812-embedded nodules were stained with uranyl acetate and lead citrate and observed by electron microscope. Scale bars, $20 \mu \mathrm{m}$. 
gent nodules when bacteria are going to be released inside the plant cells and most probably when the nodule endodermis surrounds almost completely the central part of the emergent nodule (see Figure 7).

\section{The ability of bacteroids to accumulate PHB} and the nitrogenase activity of symbiosomes are strongly affected by the ectopic expression of amtB.

The low number of undifferentiated symbiosomes observed in nodules elicited by strain CE3-pRT142, at 12 dpi, could explain the almost undetectable levels of nitrogenase activity (ARA) measured at this stage. By $21 \mathrm{dpi}$, the invaded cells of these nodules do contain symbiosomes, although at a lower number and with rarely more than one bacteroid per symbiosome (Fig. 4F). However, this low density of symbiosomes (which is lower than in nodules elicited by the control strain at 12 dpi; see Figures $3 \mathrm{E}$ and 4F) cannot per se explain the low ARA (Fig. 2B). Moreover, there are few PHB deposits in the cytoplasm of the bacteroids of CE3-pRT142 induced nodules (Figs. 4F, 5D). PHB is accumulated as a means of carbon and reductive-power storage in bacteria with a low-efficiency tricarboxylic acid cycle such as $R$. etli (for references, see Ce- vallos et al. 1996) and it is known that bacteroids may accumulate PHB and reduce $\mathrm{N}_{2}$ simultaneously (Wong and Evans 1971). Since both functions require large amounts of reductive power it is obvious that they will compete for the reducing equivalents. In fact, it has previously been shown (Cevallos et al. 1996) that the nodules elicited by an $R$. etli phaC mutant (unable to synthesize PHB) showed a 30\% higher ARA than those elicited by the wild-type strain and, in agreement with this, we observe that the cytoplasm of bacteroids of strain CFNX249 (Fix ${ }^{-}$) of $R$. etli contains a great deal of PHB (data not shown). Thus, we conclude that the symbiosomes of strain CE3-pRT142 (simultaneous induction of $a m t B$ and nif genes) show a new phenotype, characterized by the presence of less PHB deposits and a low nitrogenase activity.

\section{The ectopic expression of $a m t B$ and the uncoupling between nitrogen fixation and assimilation in symbiosomes.}

It is known that, in free-living diazotrophic bacteria, the expression of the nitrogenase complex is regulated in response to the nitrogen status of the cell (i.e., the nitrogenase activity is adapted to the requirement of $\mathrm{NH}_{4}{ }^{+}$for growth).
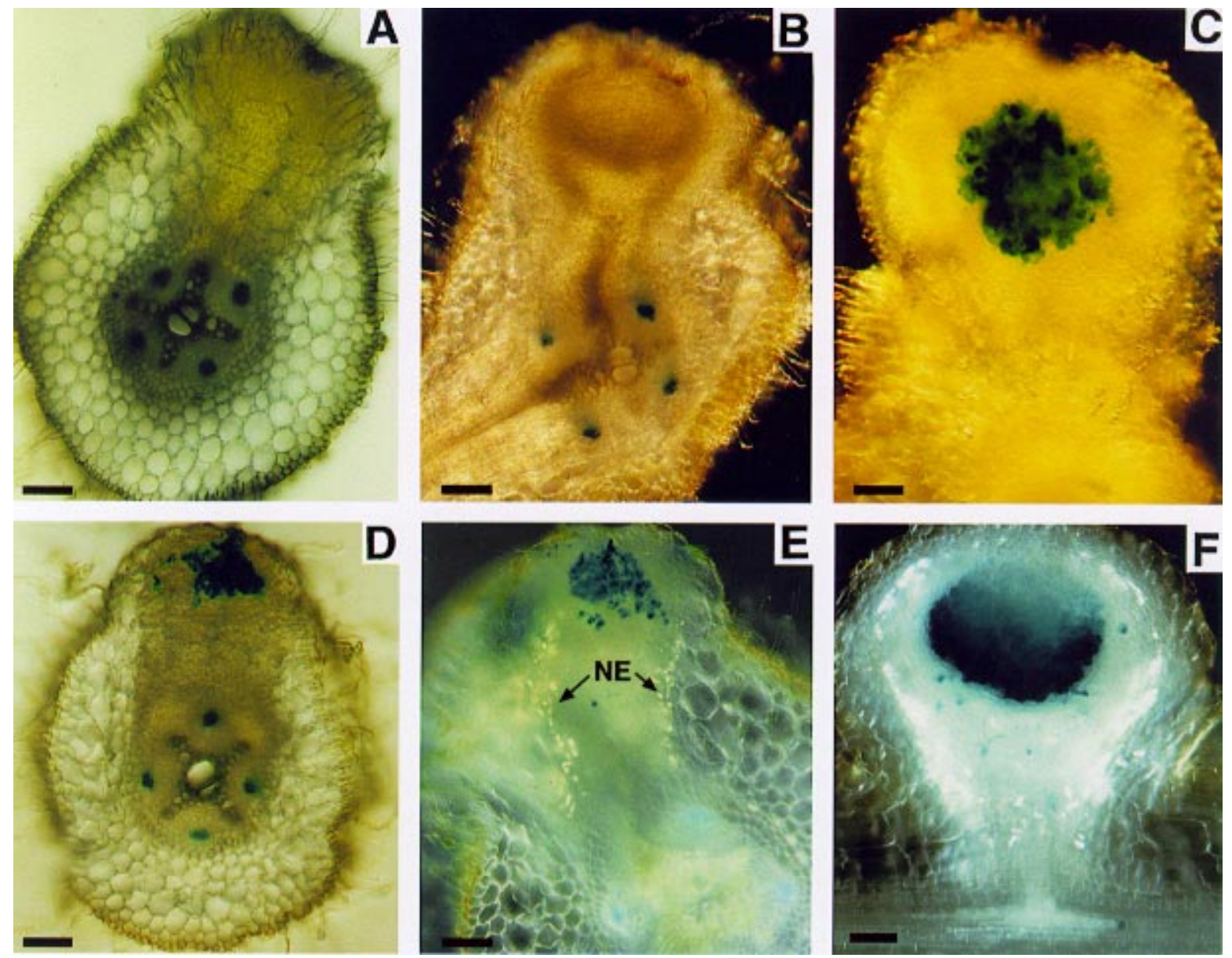

Fig. 7. A-F, The activity of the ntrBC and nifHc promoters was observed during development of nodules induced by Rhizobium etli on the roots of Phaseolus vulgaris. Transversal sections of emergent nodules at (A and D) 5, (B and $\mathbf{E}) 7$, and (C and $\mathbf{F}) 9$ days post inoculation were obtained, fixed, and immersed in a staining solution containing $1 \mathrm{mM}$ 5-bromo-4-chloro-3-indolyl $\beta$-galactopyranoside (X-Gal) as described elsewhere (Taté et al. 1998). The samples were incubated at $37^{\circ} \mathrm{C}$ for the required time, rinsed in $70 \%$ ethanol, and then photographed with a light microscope by means of brightfield and epipolarization optics. Nodules were elicited by the R. etli strains (A-C) CE3-pAR124 (pnifHc-lacZ) or (D-F) CE3-pAR66 (ntrBCp-lacZ). The nodule endodermis (NE) is indicated. Scale bars $=100 \mu \mathrm{m}$. 
This control is exerted by the $n t r$ system, which, through the control of the activity of the transcriptional regulator $\mathrm{NtrC}$, regulates the expression of the transcriptional activator NifA, which in turn activates the transcription of the nif genes (for a review, see Merrick and Edwards 1995). Moreover, it was observed that in bacteria that are fixing nitrogen, the ammonium transport (uptake or influx) system is activated, most probably to retrieve the $\mathrm{NH}_{4}{ }^{+}$ions that could be lost by simple diffusion of $\mathrm{NH}_{3}$ (for a review, see Kleiner 1985). On the other hand, the symbiosomes are nondividing, organelle-like structures programmed not only to fix nitrogen but also to release most of the nitrogen fixed. In correlation, it has been shown that, in symbiosomes of $R$. etli, the nif genes are expressed independently of the ntr system (Moreno et al. 1992) and that the transcription of amtB $\left(\mathrm{NH}_{4}{ }^{+} / \mathrm{CH}_{3} \mathrm{NH}_{3}{ }^{+}\right.$transport $)$is switched off before nitrogen fixation commences (Taté et al. 1998). Thus, during symbiosis, the $\mathrm{N}_{2}$ fixation process in bacteroids (and consequently the amount of $\mathrm{NH}_{4}^{+}$produced therein) is regulated to satisfy the plants' requirement for nitrogen.

We propose that the marked change in the process of nodule invasion and bacteroid differentiation resulting from the ectopic expression of $a m t B$ in $\mathrm{N}_{2}$-fixing bacteroids can be explained simply by considering that $\mathrm{NH}_{4}{ }^{+}$ions are retrieved from the PBS, thus generating an energy-consuming, futile cycle and/or lowering the energized state of the bacteroid membrane. The function of the nitrogenase complex (under aerobic conditions) requires energy in the form of ATP and reducing equivalents. It has previously been observed that the addition of $\mathrm{NH}_{4}{ }^{+}$to succinate-grown cells of Azotobacter vinelandii rapidly inhibits the nitrogenase activity (Laane et al. 1980). It was demonstrated that ammonium (added at a concentration of $0.2 \mathrm{mM}$ ) is taken up by the cells as a cation, and that the uptake of $\mathrm{NH}_{4}{ }^{+}$decreases the flow of reducing equivalents for nitrogenase. Moreover, at a concentration higher than $0.5 \mathrm{mM}$, ammonium also reduces the intracellular ATP/ADP ratio (Laane et al. 1980). In contrast, at concentration of even $10 \mathrm{mM}$ of $\mathrm{NH}_{4}{ }^{+}$, no effect on the nitrogenase activity of isolated bacteroids of Rhizobium leguminosarum was observed. Since isolated bacteroids showed undetectable levels of $\mathrm{NH}_{4}{ }^{+}$uptake activity, it was concluded that ammonium can affect the energized state of the cell membrane only when it is taken up (Laane et al. 1980). Thus, the presence in bacteroids of an active mechanism for the uptake of $\mathrm{NH}_{4}^{+}$(by expressing amtB ectopically), could inhibit the formation of reducing equivalents and ATP, altering not only the nitrogenase activity but also the capacity of bacteria to divide at normal rates during the invasion process, and to accumulate storage material such as PHB. In addition, the internal assimilation of $\mathrm{NH}_{4}^{+}$(via GS and consuming ATP) should stimulate the $\mathrm{NH}_{4}{ }^{+}$uptake activity and enlarge the energy problems of bacteroids. This hypothesis is substantiated by the partial effect observed when the expression of $a m t B$ was forced in bacteroids of strain CFN2012 ( $n$ trC), which showed lower intracellular levels of GS activity than its wild-type parent CE3.

Nevertheless, it is clear that the transcriptional downregulation of the $a m t B$ gene (and hence of $\mathrm{NH}_{4}{ }^{+}$uptake), occurring just when bacteria are released from the ITs into the invaded host cell (Taté et al. 1998), is essential for an effective symbiotic interaction.

\section{MATERIALS AND METHODS}

\section{Bacterial strains and media.}

Rhizobium etli (formerly Rhizobium leguminosarum bv. phaseoli; Segovia et al. 1993) strains were grown at $30^{\circ} \mathrm{C}$ in TYR medium containing the following $\left(\mathrm{g} \mathrm{liter}^{-1}\right)$ : tryptone (5), yeast extract (3), and $\mathrm{CaCl}_{2} \cdot 2 \mathrm{H}_{2} \mathrm{O}(0.88)$. E. coli strains were grown at $37^{\circ} \mathrm{C}$ in $\mathrm{TY}$ medium containing the following (g liter $^{-1}$ ): tryptone (10), yeast extract (5), and $\mathrm{NaCl}$ (10). Antibiotics used were $\left(\mu \mathrm{g} \mathrm{ml}^{-1}\right)$ : tetracycline (5); nalidixic acid (20), ampicillin (100). All media were solidified with $1.5 \%$ agar (Difco, Detroit, MI).

\section{Generation of amtB-expressing vectors.}

We have used derivatives of the plasmid pTR102 (see Figure 2), which specifies tetracycline resistance and was found to be very stable in both free-living and symbiotic bacteria cells (Weinstein et al. 1992). We also used the $R$. etli nifHc promoter (nifH gene codes for a subunit of the nitrogenase complex) that is activated under symbiotic conditions (Quinto et al. 1985; Valderrama et al. 1996).

Plasmid pRT140 (carrying the $a m t B$ gene but without its promoter) was constructed as follows: plasmid pAR139, a pGEM7Zf $^{+}$(Promega, Madison, WI) derivative carrying a complete version of the $R$. etli amtB gene, was constructed by ligation of the 1.3-kb HindIII DNA fragment from plasmid pAR124 to HindIII-digested pAR132. Plasmids pAR124 and pAR132 have been described elsewhere (Taté et al. 1998). Plasmid pAR140 was constructed by ligation of the $1.9-\mathrm{kb}$ XbaI/NsiI DNA fragment from pAR139 to XbaI/PstI-digested pMP220 (Spaink et al. 1987). Plasmid pRT140 was constructed by ligation of the $1.9-\mathrm{kb}$ BglII/BamHI DNA fragment from pAR140 to BamHI-digested pTR102.

Plasmid pRT142 (carrying the R. etli amtB gene under the control of the $\mathrm{R}$. etli pnifHc) was obtained as follows: plasmid pRT123, containing the nifHc gene of $R$. etli fused to lacZ, was constructed by ligation of the $1.5-\mathrm{kb} B g l \mathrm{II}$ DNA fragment from plasmid pCQ23 (Quinto et al. 1985) to BamHI-digested pGEM3Z (Promega), followed by digestion with EcoRI/XbaI and recloning into plasmid pMP220 (Spaink et al. 1987). Plasmid pAR142 was obtained by ligation of a 1.3-kb EcoRI/ XbaI DNA fragment from pRT123 into plasmid pAR140 digested with the same enzymes. Plasmid pRT142 was constructed by ligation of the $3.2-\mathrm{kb} B g / \mathrm{II} / \mathrm{BamHI}$ DNA fragment from plasmid pAR142 in BamHI-digested pTR102.

Plasmid pAR187 (carrying an in-frame deleted version of amtB gene under the control of the $\mathrm{R}$. etli pnifHc) was obtained as follows: plasmid pAR146 was constructed by digesting plasmid pAR139 with SalI, and religating. Plasmid pAR186 was constructed by ligation of the 1.6-kb XbaI/ BamHI DNA fragment from plasmid pAR146 to XbaI/BamHIdigested pAR123. Plasmid pAR187 was constructed by ligation of the 2.9-kb $B g l \mathrm{II} / \mathrm{BamHI}$ DNA fragment from plasmid pAR186 to BamHI-digested pTR102.

Plasmid pAR188 (carrying the pnifHc alone) was obtained by digesting plasmid pAR187 with HindIII and religating.

\section{Transformation of $R$. etli.}

Strain CE3 of $R$. etli was grown at $30^{\circ} \mathrm{C}$ with shaking (250 rpm; G-76 rotary shaker; New Brunswick, New Brunswick, NY) in TYR medium, and competent cells for electroporation 
were prepared as previously described (Taté et al. 1997). DNA of plasmids was purified with a Qiagen column (Promega). Electroporation was performed as previously described (Taté et al. 1997) with a Gene Pulser apparatus (Bio-Rad Laboratories, Richmond, CA). Electroporated cells were resuspended in $1 \mathrm{ml}$ of a rich medium containing the following $\left(\mathrm{g} \mathrm{liter}^{-1}\right)$ : tryptone (20), yeast extract (3), $\mathrm{KCl}(0.19), \mathrm{CaCl}_{2}$ (2.1), $\mathrm{MgSO}_{4}$ (2.5), and mannitol (10). The cells were incubated with shaking (as described above) for $4 \mathrm{~h}$ at $30^{\circ} \mathrm{C}$ and then plated on TYR agar containing tetracycline.

Nodulation test, plasmid stability, and nitrogenase activity.

Seeds of common beans (Phaseolus vulgaris cv. Negro Jamapa) were surface sterilized with $5 \%$ hydrogen peroxide for $30 \mathrm{~min}$, washed extensively with sterile water, and germinated at $23^{\circ} \mathrm{C}$ for $72 \mathrm{~h}$ on a petri dish containing wateragar $(1 \%)$. Germinated seeds were inoculated with the appropriate $R$. etli strains resuspended, in the nitrogen-free Jensen medium (Jensen 1942), to a final $\mathrm{OD}_{590}$ of 0.1. Plants were cultured in a growth chamber maintained at 70 to $80 \%$ relative humidity, $23^{\circ} \mathrm{C}$ in light, $19^{\circ} \mathrm{C}$ in dark, and with a 16-h daylight period.

To test plasmid stability during nodulation (without selective pressure) nodules ( 5 nodules per plant, 5 plants) were excised from roots $(21 \mathrm{dpi})$. The nodules were surface sterilized (5\% sodium hypochlorite treatment for $1 \mathrm{~min}, 70 \%$ ethanol for $1 \mathrm{~min}$, and two rinses with sterile water) and crushed in $100 \mu \mathrm{l}$ of TYR medium in multiple-well plates (Corning, Corning, NY) with a single nodule for each well. Cell suspensions were then diluted and plated on TYR agar supplemented either with nalidixic acid $\left(20 \mu \mathrm{g} \mathrm{ml}^{-1}\right)$ or with nalidixic plus tetracycline $\left(5 \mu \mathrm{g} \mathrm{ml}^{-1}\right)$. Less than $0.5 \%$ of the total bacteria reisolated were tetracycline sensitive and showed no plasmid by gel electrophoresis.

Nitrogenase activity was determined by measuring acetylene reduction of nodulated roots. Plants were harvested, and the root system was immediately detached and incubated, in five replicates, at $25^{\circ} \mathrm{C}$, in $15-\mathrm{ml}$ rubber-cap tubes containing $1 / 10(\mathrm{vol} / \mathrm{vol})$ acetylene. The ethylene produced at different time points was quantified with a Sigma $3 \mathrm{~B}$ gas chromatograph (Perkin-Elmer, Foster, CA).

\section{Electron and optical microscopy.}

At various times after infection, individual nodules located on the primary root (the largest at each stage of development) were excised from the root, sliced manually, and fixed immediately in $50 \mathrm{mM}$ potassium phosphate buffer ( $\mathrm{pH} \mathrm{7.4)} \mathrm{con-}$ taining $4 \%$ paraformaldehyde, $3 \%$ glutaraldehyde, and $4 \%$ sucrose. The samples in fixative were submitted to short pulses of gentle vacuum until they sank. After $3 \mathrm{~h}$, the nodules were rinsed in the same buffer, post-fixed $1 \mathrm{~h}$ in $50 \mathrm{mM}$ potassium phosphate buffer ( $\mathrm{pH}$ 7.4) containing $1 \%$ osmium tetroxyde, rinsed three times in the same buffer, dehydrated by passing through a graded ethanol series, and embedded in Poly/Bed 812 resin (Polyscience, Warrington, PA). Ultrathin sections were cut with a Reichert OMU2 microtome equipped with a diamond knife, stained with uranyl acetate and lead citrate, and observed in a Philips EM208 electron microscope. Semi-thin sections ( 1 to $2 \mu \mathrm{m}$ thick) of the same samples were used for optical observation after staining with blue toluidine (0.04\% in distilled water).

\section{ACKNOWLEDGMENTS}

This work was partially supported by grants from CEE (EURATINE:BIOTEC94-2310) and Progetto Strategico 'Controlli posttranscrizionali dell'espressione genica', CNR (Italy). M. M. acknowledges support from the BBSRC via a grant to the John Innes Centre. We thank F. Graziani for useful discussion, M. L. Girard for providing strain CFNX249 of R. etli, O. Piedimonte for help with the figures, and C. Sole for technical assistance.

\section{LITERATURE CITED}

Bravo, A., Becerril, B., and Mora, J. 1988. Introduction of the Escherichia coli gdhA gene into Rhizobium phaseoli: Effect on nitrogen fixation. J. Bacteriol. 170:985-988.

Brown, C. M., and Dilworth, J. M. 1975. Ammonia assimilation by Rhizobium cultures and bacteroids. J. Gen. Microbiol. 86:39-48.

Cevallos, M., Encarnacion, S., Leija, A., Mora, Y., and Mora, J. 1996. Genetic and physiological characterization of a Rhizobium etli mutant strain unable to synthesize poly- $\beta$-hydroxybutyrate. J. Bacteriol. 178:1646-1654.

Glenn, A. R., and Dilworth, M. J. 1984. Methylamine and ammonium transport systems in Rhizobium leguminosarum MNF 3841. J. Gen. Microbiol. 130:1961-1968.

Howitt, S. M., Udvardi, M. K., Day, D. A., and Gresshoff, P. M. 1986. Ammonia transport in free-living and symbiotic Rhizobium sp. ANU289. J. Gen. Microbiol. 132:257-261.

Jensen, H. L. 1942. Nitrogen fixation in leguminous plants. General characters of root-nodule bacteria isolated from species of Medicago and Trifolium in Australia. Proc. Linn. Soc. NSW 66:98-108.

Kaiser, B. N., Finnegan, P. M., Tyerman, S. D., Whitehead, L. F., Bergersen, F. J., Day, D. A., and Udvardi, M. K. 1998. Characterization of an ammonium transport protein from the peribacteroid membrane of soybean nodules. Science 281:1202-1206.

Kleiner, D. 1985. Bacterial ammonium transport. FEMS Microbiol. Rev. 32:87-100.

Laane, C., Krone, W., Konings, W., Haaker, H., and Veeger, C. 1980. Short-term effect of ammonium chloride on nitrogen fixation by Azotobacter vinelandii and by bacteroids of Rhizobium leguminosarum. Eur. J. Biochem. 103:39-46.

Marini, A.-M., Vissers, S., Urrestarazu, A., and Andre, B. 1994. Cloning and expression of the $M E P 1$ gene encoding an ammonium transporter in Saccharomyces cerevisiae. EMBO J. 13:3456-3463.

Mendoza, A., Leija, A., Martínez-Romero, E., Hernández, G., and Mora, J. 1995. The enhancement of ammonium assimilation in Rhizobium etli prevents nodulation of Phaseolus vulgaris. Mol. Plant-Microbe Interact. 8:584-592.

Mendoza, A., Valderrama, B., Leija, A., and Mora, J. 1998. NifAdependent expression of glutamate dehydrogenase in Rhizobium etli modifies nitrogen partitioning during symbiosis. Mol. Plant-Microbe Interact. 11:83-90.

Merrick, M., and Edwards, R. 1995. Nitrogen control in bacteria. Microbiol. Rev. 59:604-622.

Moreno, S., Patriarca, E. J., Chiurazzi, M., Meza, R., Defez, R., Iaccarino, M., and Espin, G. 1992. Phenotype of a Rhizobium ntrC mutant. Res. Microbiol. 143:161-171.

Ninnemann, O., Jauniaux, J.-C., and Frommer, W. B. 1994. Identification of a high affinity $\mathrm{NH}_{4}^{+}$transporter from plants. EMBO J. 13: 3464-3471.

Panagiota, M., Pawlowski, K., and Bisseling, T. 1995. Symbiotic nitrogen fixation. Plant Cell 7:869-885.

Patriarca, E. J., Chiurazzi, M., Manco, G., Riccio, A., Lamberti, A., De Paolis, A., Rossi, M., Defez, R., and Iaccarino, M. 1992. Activation of the Rhizobium leguminosarum glnII gene by $\mathrm{NtrC}$ is dependent on upstream DNA sequences. Mol. Gen. Genet. 234:337-345.

Patriarca, E. J., Riccio, A., Colonna-Romano, S., Defez, R., and Iaccarino, M. 1994. DNA binding activity of NtrC from Rhizobium grown on different nitrogen sources. FEBS Lett. 354:89-92.

Patriarca, E. J., Riccio, A., Taté, R., Colonna-Romano, S., Iaccarino, M., and Defez, R. 1993. The ntrBC genes of Rhizobium leguminosarum are part of a complex operon subject to negative autoregulation. Mol. Microbiol. 9:569-577.

Patriarca, E. J., Taté, R., Fedorova, E., Riccio, A., Defez, R., and Iac- 
carino, M. 1996. Down-regulation of the Rhizobium ntr system in the determinate nodule of Phaseolus vulgaris identifies a specific developmental zone. Mol. Plant-Microbe Interact. 9:243-251.

Quinto, C., De La Vega, H., Flores, M., Leemans, J., Cevallos, M., Pardo, M. A., Azpiroz, R., Girard, M. L., Calva, E., and Palacios, R. 1985. Nitrogenase reductase: A functional multigene family in Rhizobium phaseoli. Proc. Natl. Acad. Sci. UDSA 82:1170-1174.

Segovia, L., Young, J. P. W., and Martinez-Romero, E. 1993. Reclassification of American Rhizobium leguminosarum biovar phaseoli type I strains as Rhizobium etli sp. nov. Int. J. Syst. Bacteriol. 43:374-377.

Siewe, R. M., Weil, B., Burkovski, A., Eikmanns, B. J., Eikmanns, M., and Kramer, R. 1996. Functional and genetic characterization of the (methyl)ammonium uptake carrier of Corynebacterium glutamicum. J. Biol. Chem. 271:5398-5403.

Soupene, E., He, L., Yan, D., and Kustu, S. 1998. Ammonia acquisition in enteric bacteria: Physiological role of the ammonium/methylammonium transport B (AmtB) protein. Proc. Natl. Acad. Sci. USA 95:7030-7034.

Spaink, H. P., Okker, R. J. H., Wijffelman, C. A., Pees, E., and Lugtenberg, B. J. J. 1987. Promoters in the nodulation region of the Rhizobium leguminosarum Sym plasmid pRL1JI. Plant Mol. Biol. 9:27-39.

Taté, R., Patriarca, E. J., Riccio, A., Defez, R., and Iaccarino, M. 1994. Development of Phaseolus vulgaris root nodules. Mol. Plant-Microbe Interact. 7:582-589.

Taté, R., Riccio, A., Iaccarino, M., and Patriarca, E. J. 1997. A cysG mutant strain of $R$. etli pleiotropically defective in sulfate and nitrate assimilation. J. Bacteriol. 179:7343-7350.

Taté, R., Riccio, A., Merrick, M., and Patriarca, E. J. 1998. The Rhizobium etli amtB gene coding for an $\mathrm{NH}_{4}{ }^{+}$transporter is down-regulated early during bacteroid differentiation. Mol. Plant-Microbe Interact. 11:188-198.
Tyerman, S. D., Whitehead, L. F., and Day, D. A. 1995. A channel-like transporter for $\mathrm{NH}_{4}{ }^{+}$on the symbiotic interface of $\mathrm{N}_{2}$-fixing plants. Nature 378:629-632.

Udvardi, M. K., and Day, D. A. 1997. Metabolite transport across symbiotic membranes of legume nodules. Annu. Rev. Plant Physiol. Plant Mol. Biol. 48:493-523.

Valderrama, B., Davalos, A., Girard, M. L., Morett, E., and Mora, J. 1996. Regulatory proteins and cis-acting elements involved in the transcriptional control of Rhizobium etli reiterated nif genes. J. Bacteriol. 178:3119-3126.

Van Heeswijk, W. C., Howing, S., Molenaar, D., Stegeman, B., Kahn, D., and Westerhoff, H. V. 1996. An alternative $P_{\text {II }}$ protein in the regulation of glutamine synthetase in Escherichia coli. Mol. Microbiol. 21:133-146.

Van Rhijn, P., and Vanderleyden, J. 1995. The Rhizobium-plant symbiosis. Microbiol. Rev. 59:124-142.

Vasse, J., de Billy, F., Camut, S., and Truchet, G. 1990. Correlation between ultra-structural differentiation of bacteroids and nitrogen fixation in alfalfa nodules. J. Bacteriol. 172:4295-4306.

Verma, D. P. S. 1992. Signals in root nodule organogenesis and endocytosis of Rhizobium. Plant Cell 4:373-382.

Weinstein, M., Roberts, R. C., and Helinski, D. R. 1992. A region of the broad-host-range plasmid RK2 causes stable in planta inheritance of plasmids in Rhizobium meliloti cells isolated from alfalfa root nodules. J. Bacteriol. 174:7486-7489.

Wong, P. P., and Evans, H. 1971. Poly- $\beta$-hydroxybutyrate utilization by soybean nodules and assessment of its role in maintenance of nitrogenase activity. Plant Physiol. 47:750-755.

Yang, W.-C., Horvath, B., Hontelez, J., Van Kammen, A., and Bisseling, T. 1991. In situ localization of Rhizobium mRNAs in pea root nodules: nifA and nifH localization. Mol. Plant-Microbe Interact. 4:464-468. 